\title{
Artelogie
}

artelogie Recherche sur les arts, le patrimoine et la littérature de l'Amérique latine

1 | 2011

Brésil, questions sur le modernisme

\section{Trayectoria de una obra: "A negra" (1923) de Tarsila do Amaral. Una revolución icónica}

\author{
Edgard Vidal
}

\section{OpenEdition}

Journals

Edición electrónica

URL: https://journals.openedition.org/artelogie/8562

DOI: $10.4000 /$ artelogie.8562

ISSN: 2115-6395

Editor

Association ESCAL

Referencia electrónica

Edgard Vidal, «Trayectoria de una obra: "A negra" (1923) de Tarsila do Amaral. Una revolución icónica», Artelogie [En línea], 1 | 2011, Publicado el 01 marzo 2011, consultado el 05 abril 2023. URL: http:// journals.openedition.org/artelogie/8562 ; DOI: https://doi.org/10.4000/artelogie.8562

Este documento fue generado automáticamente el 5 abril 2023.

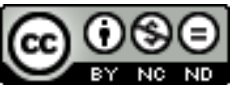

Creative Commons - Atribución-NoComercial-SinDerivadas 4.0 Internacional - CC BY-NC-ND 4.0 https://creativecommons.org/licenses/by-nc-nd/4.0/ 


\title{
Trayectoria de una obra: "A negra" (1923) de Tarsila do Amaral. Una revolución icónica
}

\author{
Edgard Vidal
}

1 El titulo de este artículo plantea algunas interrogantes que quisiera elucidar a modo de preámbulo. Hablamos muy comúnmente de trayectoria de personas (importantes o no) utilizando una metodología de historias de vidas extraída de los archivos en el caso de las ciencias históricas a través del estudio de redes de conocimiento o de vínculos. 0 en la disciplina sociológica, gracias a entrevistas, a partir del análisis de relaciones de grupos o de clases. La indagación de las trayectorias que estamos proponiendo actualmente, se ubica por una parte, en lo que podría ser una historia de los soportes de conocimiento en la línea de la historia del libro considerando las prácticas de lectura que determinan "apropiaciones" disímiles que dependen de las habilidades intelectuales de una comunidad de lectores, las estrategias del autor, el formato del texto1. Pero por otra parte utilizamos los trabajos de la sociología de la lectura, estudiando como las características políticas o culturales (del mismo modo que la situación socio-demográfica, el nivel de la educación, etc.) afectan la recepción².

2 En este artículo se trata de examinar la recepción de un cuadro a través de la temática de la influencia. Que es lo que dicen los críticos de quien o qué ha incidido sobre esa obra. Este procedimiento implica un juego sutil con el tiempo que es el material propio de la historia, porque esta historia de la recepción implica un movimiento espiralado que va de la obra hacia el futuro de su recepción siempre abierto y vuelve por el camino del análisis al pasado del precursor (o de los precursores) del artista y de su cuadro. La obra plástica esta entonces en el centro de nuestra atención. En este sentido, en musicología por ejemplo, otros trabajos han sido pioneros en esta vía ${ }^{3}$. Pero, en nuestro análisis, el pintor o el autor, es también tomado como un objeto textual, a partir de lo relatado sobre él, en la recepción o en las biografías ${ }^{4}$.

3 El estudio sobre las fuentes los hemos agrupado en dos tipos, los diarios y revistas parisinos de la década del 20 y los libros y ensayos sobre « a negra » publicados entre 
los años 60 y hoy en día. Dejaremos de lado la descripción del aspecto tecnológico del estudio, la interrelación de una base iconológica y una base de datos bibliográfica para abordar a modo de preámbulo el aspecto epistemológico, la noción de objeto estético y de como este actúa en relación con su crítica.

\section{El objeto estetico}

4 Este procedimiento que estamos proponiendo es un examen de la crítica de arte basado en la reflexión que sobre los objetos ${ }^{5} \mathrm{y}$ los sistemas de información, han trabajado las ciencias del hombre, en particular la arqueología y le etnología, así como las observaciones posteriores venidas de la filosofía ${ }^{6}$. Hemos tratado este tema en profundidad, en particular de la epistemología del objeto literario y textual en otros trabajos ${ }^{7}$. Se trata ahora de investigar cómo la crítica trata las influencias que permiten a los procesos creativos de tomar sentido. La obra adquiere en este caso, una importancia heurística porque participa a la producción de significado propio à la crítica y a la historia del arte. Esta elaboración crítica puede realizarse a partir de la figura del pintor pero también a partir de una unidad semiótica, el cuadro. Pero también puede tratarse de un estudio de una parte de éste, un detalle o un trazo. Esta segmentación intencional tiene un riesgo, inherente a cualquier delimitación de la problemática, que es al cabo una elección subjetiva, es decir la definición del perímetro del estudio. Por otra parte, ya que cada objeto está incluido en una unidad más grande (la serie de pinturas de un mismo pintor para el cuadro, la escuela de la cual el pintor hace parte, el contexto o el museo en el cual la pintura se expone), toda fragmentación de la unidad significativa (en este caso por ejemplo el cuadro de "a negra") es una determinación subjetiva.

5 Hemos aceptado cierto reduccionismo porque este nos permite por una parte crear series comparativas del objeto estético con otros objetos de la misma pintora (así a fines del análisis se podrán confrontar, por ejemplo una serie de retratos de Tarsila de diferentes periodos). Pero también cotejaremos "A negra" con retratos similares de la misma categoría pero de pintores y de periodos distintos ("a negra" y otros retratos de pintores modernistas).

Gracias a esta posibilidad de crear series y de incluir estas series en unidades mas grandes (un estudio de la recepción del pintor y de la escuela en la época en que el objeto toma vida) nos permite atenuar el reduccionismo que podría ser el talón de Aquiles de nuestra metodología. Para estudiar estas dos amplificaciones propias al objeto (de un cuadro a un grupo o a todos los cuadros del autor, y de éste a la escuela) vamos primero a analizar la recepción de Tarsila en París y como esta es ubicada en el panorama de las artes francesas de la primera mitad del siglo XX. Para terminar, trataremos de conceptualizar el termino de "confluencias artísticas" prefriéndolo al de "influencias".

\section{La decada de los años veinte}

7 Tarsila viaja a París entre 1920 y 1922, volviendo luego de la disolución del "Grupo dos cinco" en 1923 hasta 1926, año de su casamiento con Oswald de Andrade. Es entonces en su segundo viaje a París, que es pintada "La negra" obra sobre la cual trabajaremos. 
“A negra” de Tarsila do Amaral, 1923

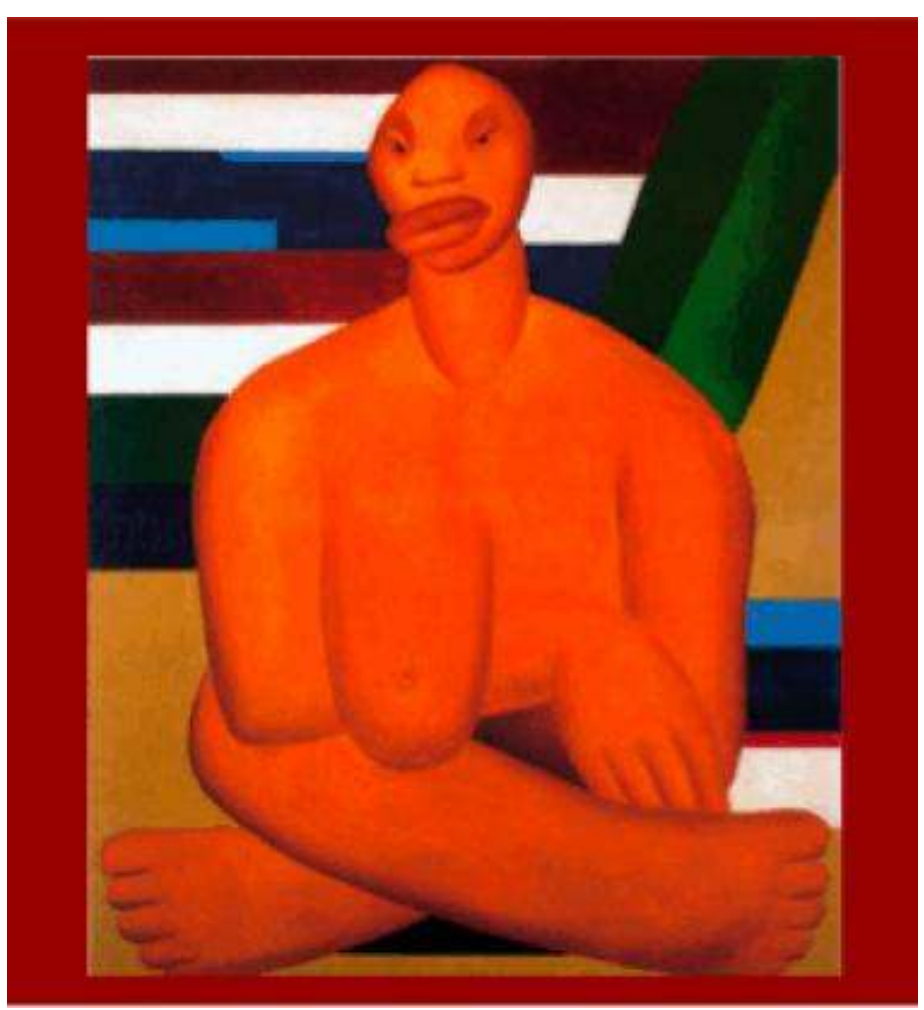

Esta es una tela considerada cubista pero ha sido también llamada la primera tela constructivista, surrealista, antropofágica "avant la lettre", inaugurando el primitivismo brasileño y en fin siendo un manifiesto modernista ${ }^{8}$. Funciona en múltiples niveles de representación, dicen otros es una alegoría (cristiana?) o maternidad (afro-brasileña), es un tótem pagano cuya poesía emana de la extrañeza del Otro de lo primitivo y latente, pero es también alegoría nacional, cartel publicitario, producto de exportación, cromo patriarcal, madre ancestral, contraste de formas, fetiche sexual y claro icono visual de los valores negros ${ }^{9}$. Nos limitaremos a ordenar esa profusión de criticas en torno de los campos semánticos nacional-cosmopolita como lo hemos planteado con el grupo de la revista Artelogie, a partir de los trabajos de Jacques Leenhard, Mônica Pimenta Velloso, Nadia Weber Santos, Daniela Fialho, Christine Frérot, Aline Miklos. Este grupo analiza la modernidad brasileña estudiándola como una multiplicidad de campos de tensión que han causado una efervescencia de innovaciones, fertilizando con sus producciones, todo el siglo $\mathrm{XX}^{10}$. Así la particularidad de la creación literaria y artística modernista se manifestaría en la tensión de esos diversos campos de fuerza, tales que el nacionalismo y el universalismo o la oposición "cultura popular"/"cultura académica" (que también es muy importante en esta pintura).

9 Tarsila, Tarsila, Tarsila!. En París de los años 20 se hablaba en pintura brasileña de Do Rego Monteiro y de Do Amaral. A ésta última se la llamaba por su nombre, y se la relacionaba siempre, para bien o para mal, con lo mejor de la élite cubista. Figurará en diferentes diarios y boletines: Mercure de France, La Renaissance, La Femme de France ('puis' Mode et beauté), Le Bulletin de la vie artistique, Bulletin de L'Effort moderne, Bibliographie de la France y la Revue de l'Amérique Latine. 
Dos eventos importantes están relacionados con esta difusión entre los años 1923 y 1928: uno es el libro de Cendrars "Feuille de route", donde en la tapa constaba una ilustración de Tarsila y su nombre muy visible en la frase "Dessins de Tarsila" (1924). El otro es la exposición de Tarsila entre el 7 al 23 de junio de 1926 en la Galerie Percier.

“Feuilles de route", 1924, Blaise Cendrars

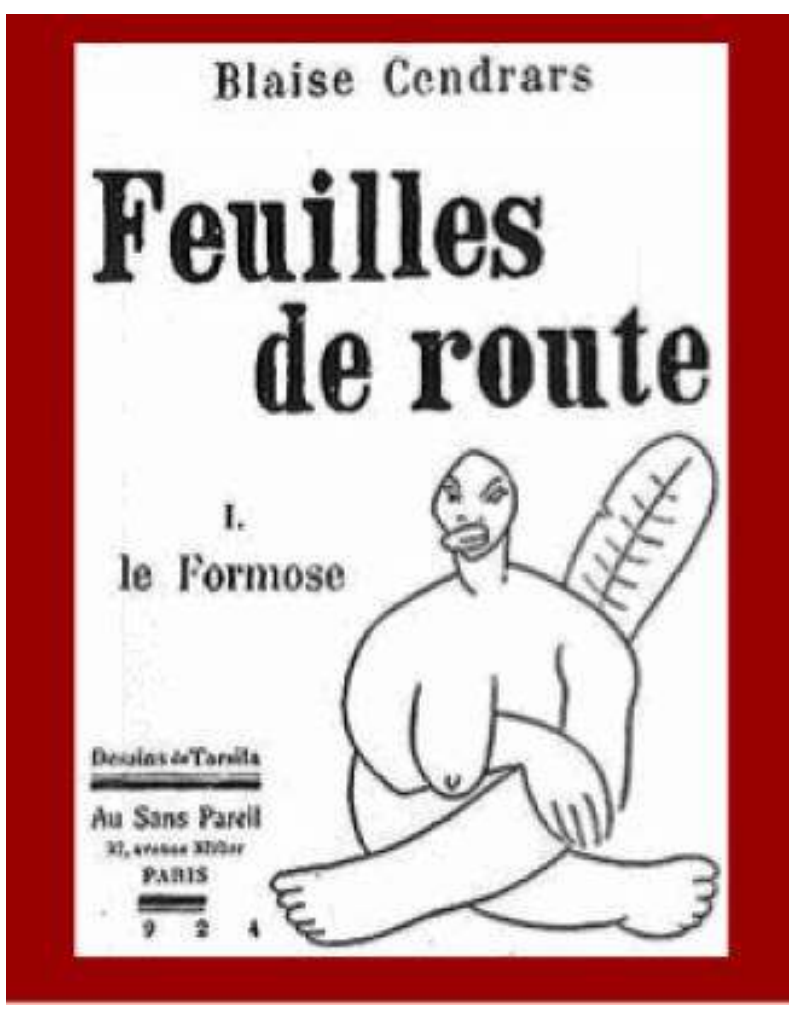

En La Renaissance de l'art français et des industries de luxe, por ejemplo, en el número de junio de 1926 (p.368) hay dos reproducciones de cuadros de la exposición de la Galeria Percier ("Lagoa Santa" y "Paysages") y en el número del mes siguiente, hay dos reproducciones de cuadros de Do Rego Monteiro, uno de Malfatti y uno de Tarsila ("El vendedor de frutas", p. 470). Pero en realidad, el texto de presentación de las reproducciones, muestra marcadas preferencias primero, para el Sr. Do Rego Monteiro que realiza una obra plástica "original y poderosa". Luego, Tarsila merece varias líneas donde el autor se centra en la influencia que tiene sobre esta pintora Fernand Léger. Tarsila lograría ser más sensible, menos cerebral que el pintor francés. "Muy pronto se va descubriendo en la Srta. Tarsila, bajo esa estilización, una elegancia, una delicadeza muy femenina. Mucho se puede esperar de esta artista." (p. 471)

Anita Malfatti, sin embargo, esta citada entre varios sin comentarios: "Citemos aún a la Sra. Malfatti, Sres. Dutra, Belmiro, Colin, Madruga." Este artículo fue firmado por Raymond Cogniat, del cual un artículo muy interesante ha sido escrito por Dilma Castelo Branco Diniz. de la Universidade Federal de Minas Gerais. 
La Renaissance de l'art français et des industries de luxe, junio de 1926 (p.368) donde se encuentra la reproducción de "El vendedor de frutas"

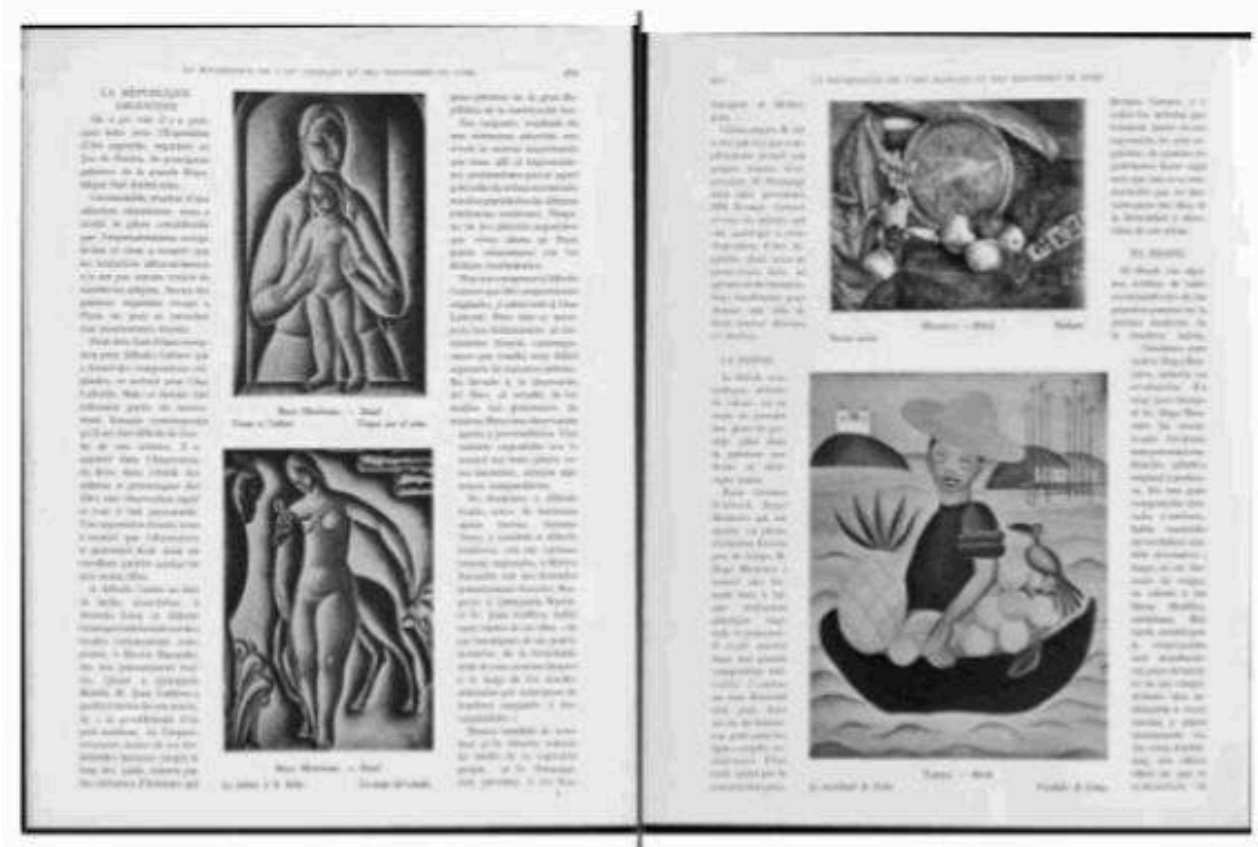

En conclusión, Zina Aita no tendrá ninguna referencia en las fuentes estudiadas en ese periodo y para Cavalcanti habrá que esperar la década de 1930 con dos citaciones, solo Do Rego Monteiro y Tarsila, por el Brasil, son abundantemente citados y con reproducciones publicadas. Pero Tarsila es muy conocida también como alumna del cubismo, así es presentada en la La Renaissance: politique, littéraire et artistique (p. 15) donde Bernard Colrat, publica en Paris también en el 3 de noviembre de 1928. Y en el Bulletin de L'Effort moderne 1926/12, donde se publicara una de las únicas reproducciones de una obra perdida de Tarsila "Nègre adorant". Esta se encuentra entre las obras de Metzinger, Gris, Survage, Valmier, de Chirico, Picasso (dos Naturalezas Muertas de 1914 y 1918), Léger (dos cuadros de 1918: Le mécanicien et Le moteur), Tarsila (Nègre adorant) Braque una Naturaleza Muerta de 1920. La primera plana del cubismo. 


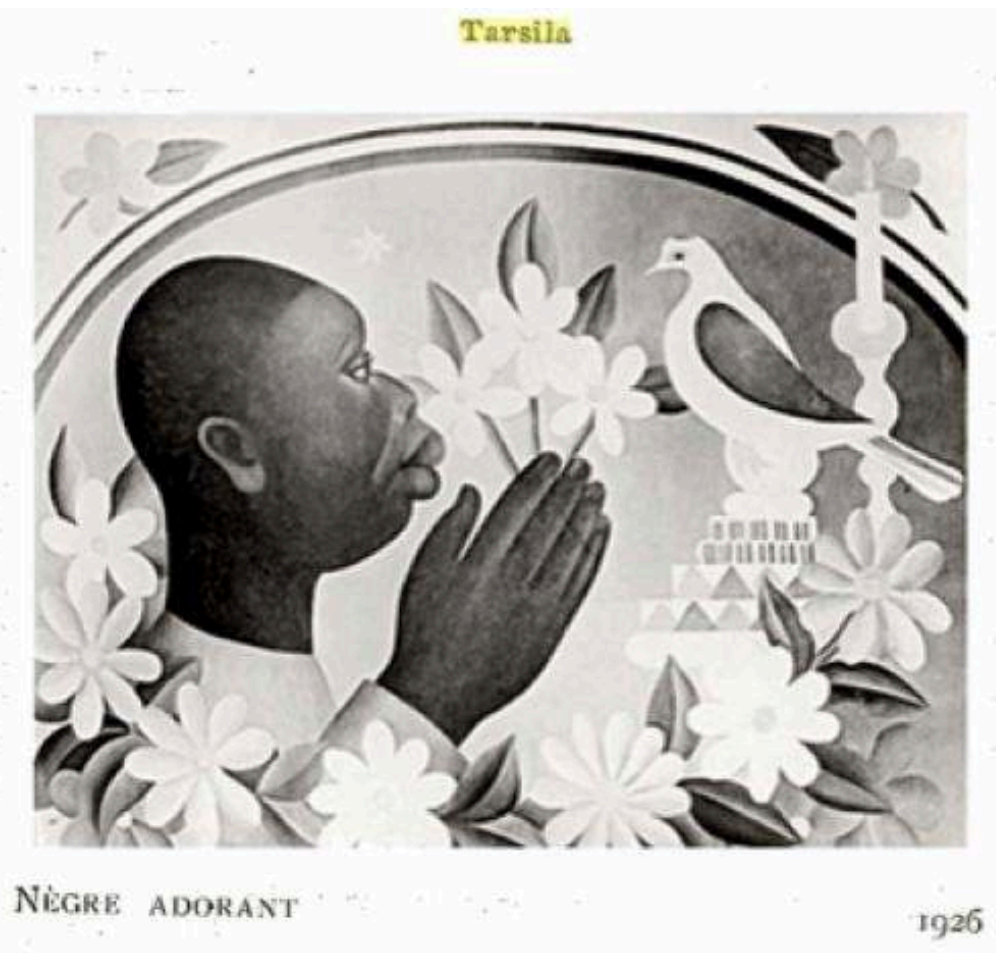

En La Renaissance: politique, littéraire et artistique del 3/11/1928 (pag.15) se la ve en el nuevo salón de los "verdaderos" independientes en el parque de exposiciones de la Puerta de Versailles, y el cronista comenta que algunos jóvenes tuvieron la idea de reunir a otros que no harán nunca parte de un salón con jurado y allí entre algunos discípulos del cubismo, encontramos a Tarsila rodeada de Gounaro, Beaudin, "un pintor armonioso" Coula Roppa -y continua el artículo- con los pintores de domingo: Rimbert, el empleado del correos y Sari, el jefe de la estación del tren.

El artículo de la Rennaissance de 1928 puede mostrarnos las primeras resistencias producidas por el importante movimiento de democratización del arte, propio al siglo que comienza, de lo cual son actores los cubistas y que hacen recaer tales críticas sobre la pintura de Tarsila $^{11}$. Porque según la revista La Femme de France (1928/12/09: 22) Tarsila en tanto que mujer a la moda en ese París de los años 20 esta muy ligada con un grupo de jóvenes "llenos de soberbia", los cubistas. Tarsila es vista en este grupo atraída por los juguetes y el exotismo, hipnotizada como todos estos jóvenes, por el ejemplo del aduanero Rousseau.

16 Para comprender los desasosiegos estéticos (que son también políticos) de esta época, nos parece ilustrativa la nota de Camille Mauclair publicada por la Revue de l'Amérique Latine del año $1926^{12}$. Este crítico narra las transformaciones de la pintura en Francia (revolucionarias según el) que van de 1875 a 1925. El paralelo con la revolución francesa (pero la revolución rusa no estaba lejos...), acompaña todo el análisis, solo que se trata de la revolución del impresionismo contra el academismo. Esta revolución pictórica preservaba todavía los valores de orden y de gusto de la escuela francesa. Pero no dura mucho todo eso, dice Mauclair, es lo propio de las revoluciones liberales de llegar a los peores extremos. Vino el puntillismo de Seurat, luego el "extraño y poderoso" Gauguin y también el loco Van Gogh. Pero la deconstrucción del sistema pictórico academicista 
encuentra en Cézanne una voluntad desmesurada, un espíritu geométrico que llevaba a una simplificación extrema de las formas, una obra frustrada en sus intentos, sintética y sofocante. Cézanne será "el gran responsable del bien y del mal entre 1900 y 1925".

No voy a prolongar mucho más la lectura de este artículo tan parcial pero también bastante interesante porque nos da una pista del juego de tensiones y de la desorientación del cambio continuo que provoca el modernismo, mas allá de la personalidad controvertida de Mauclair que termina colaborando en la Francia ocupada. Cabe preguntarse porqué esta nota fue publicada en la Revue de l'Amérique Latine. Seguramente porque a principios de siglo, como lo afirma Sergio Miceli, muchos de los mejores clientes de arte eran sudamericanos y norteamericanos. Son interesantes las constataciones sobre la importancia y la multiplicación de los Salones (Salón des Indépendants, Salón d'Automne, Salón des Tuileries, todos se crearan en los primeros años del siglo XX), sobre la democratización y la comercialización del arte. Mauclair indica que la aplicación de las prácticas publicitarias y de especulación financiera transformaban los valores del arte que habían sido conservados y respetados por los grandes artistas de todos los tiempos. Es en ese contexto que aparecen los "extremistas", los cubistas, que huían de toda imitación de la naturaleza, donde toda ley de perspectiva era prohibida bajo el termino de fotográfica. Los salones -dice este crítico- multiplicaban al infinito las manzanas de Cézanne y los retratos evitando el parecido.

En todo caso para Mauclair, la revolución pictórica, se vuelve violenta y vulgar y se hace posible una crisis de la especulación de la "bolsa de la pintura" -dice- que tiraniza los productores y que presagia un crack de no vendidos (estamos en 1926). En ese desorden son los cubistas los más extremos y los que buscan el poder a partir de un reclasificación general de las artes. Quienes son esos cubistas ? El español Picasso, es el alma de los revolucionarios y las ramificaciones de este movimiento se extienden a una serie de pequeños grupos aglomerados en Montparnasse, barrio que ha suplantado Montmartre. Esta multitud de cubistas está compuestas en su mayoría de extranjeros, que ocupan los salones de los "Indépendants" y "d'Automne". Estos son rusos, serbios, japoneses, alemanes o incluso -afirma - negros y muy frecuentemente semitas. Como conseguir una nueva cohesión de lo que el llama la Escuela Francesa -se pregunta - frente a esa "mascarada pictural donde tantos elementos internacionales entran en ebullición?". Una escuela que permita evitar el alboroto de los admiradores de la gloria cómica del aduanero Rousseau, el tumulto de las muchedumbres partidarias de la deformación y del arte negro. Es esta sin duda una critica al cubismo, pero también al proyecto de Tarsila. En ese contexto, donde la fealdad aparece como una convención de la vida social -termina Mauclair-no es de extrañar entonces que el publico haya podido espantarse de la representación de los desnudos femeninos "similares a gorilas multicolores". 


\section{La revolución pictórica}

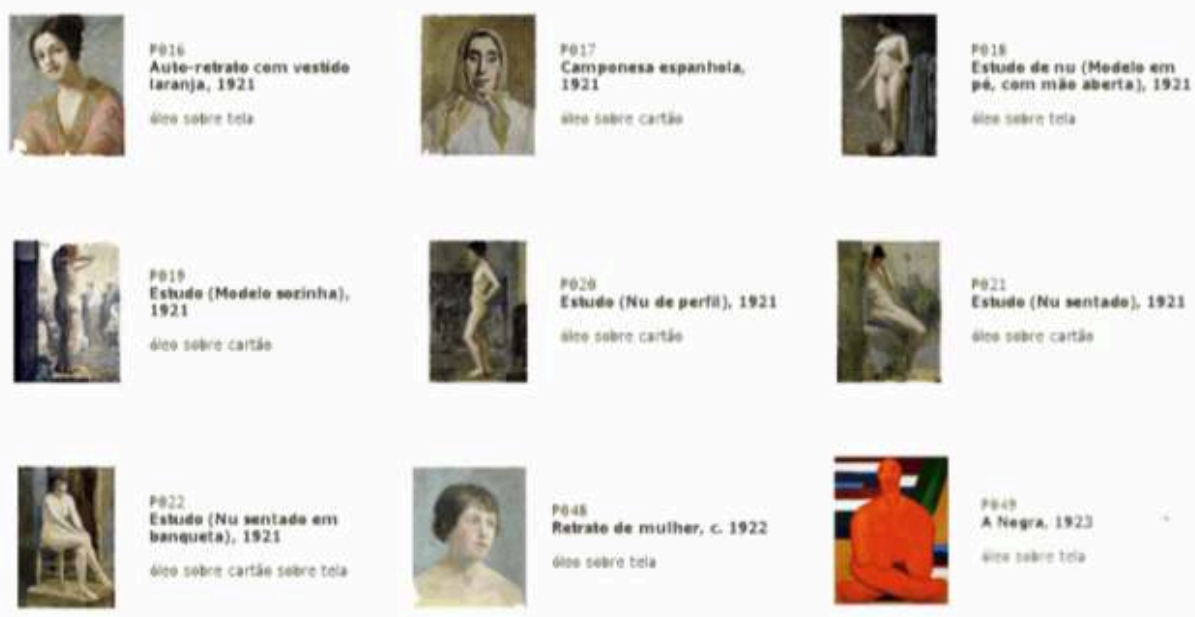

Estas imágenes pueden indicarnos lo que significaba esa revolución en la trayectoria personal de Tarsila. La pintora en el año 1923, pasa sin preámbulos del academicismo al modernismo, y de los retratos de blancos a la valorización de la figura del negro. Esta valorización es el tema dominante de son periodo parisino y la variación que realiza la pintora brasilera del primitivismo dominante en la capital luz, esta igualmente señalada en las imágenes publicadas durante los años 20: "La negra" y su reproducción para el libro de Cendrars, "Nègre adorant" ${ }^{13} \mathrm{y}$ "El vendedor de frutas" ${ }^{14}$.

Antes de terminar con los críticos de la década de 1920, quisiera glosar sobre un precursor de Tarsila que después fue muy olvidado. José Severiano de Rezende anota en la Gazette du Brésil ${ }^{15}$ que Tarsila tiene como antecedente el uruguayo Pedro Figari que exponía en la capital francesa en 1923 con suceso "sus cuadros de negros bailando, y que había comprendido el sentido folclórico de esas interpretaciones ingenuas". Y de Rezende concluye sobre Tarsila, respondiendo seguramente a las criticas que hemos visto mas arriba, que no hay que creer que tal pintura es un juego de niños. Ese trabajo sobre las masas y los volúmenes de los cuales la perspectiva no esta ausente es muy difícil y sigue un plan preconcebido de antemano." Cada parte del diseño -dice de Rezende- se inserta en un todo armonioso, gracias a una técnica estricta." 16

Otro olvidado después pero que esta muy presente en estos críticos es Gauguin. Sergio Milliet en la Revue de l'Amérique latine, $\mathrm{N}^{\circ} 9,1925$, p. 171, retomando el articulo citado anteriormente, indica que el libro 'Feuilles de route: Le formose" de Blaise Cendrars, está ilustrado con mucha gracia y talento por la pintora brasileña . "Ella -concluye-es uno de los tres grandes pintores de temas de América del sur, los otros dos son Gauguin y Pedro Figari."

22 Lo que es muy curioso de este comentario de Serge Milliet es que Gauguin es considerado como un autor de temas americanos del sur. Recordemos que la madre de 
Gauguin, hija de Flora Tristán, se refugió en Lima con su abuelo materno, donde el niño Gauguin vive hasta la edad de siete años. Luego en abril de 1887, viaja al Panama y a la isla de Taboga, y esto confiere sin duda el status de "pintor sudamericano" a Gauguin. Si la referencia a este pintor es rara en la recepción de la "negra" no son menos importantes los puntos en común entre la pintura de Tarsila y las escultura "Ídolo con una concha" e "Ídolo de la perla", en particular en sus posturas con las piernas cruzadas inspirada de las representaciones de Buda que Gauguin había visto en París durante la Exposición Universal de 1889.

Dos esculturas de Paul Gauguin, Idole à la coquille, (1892)
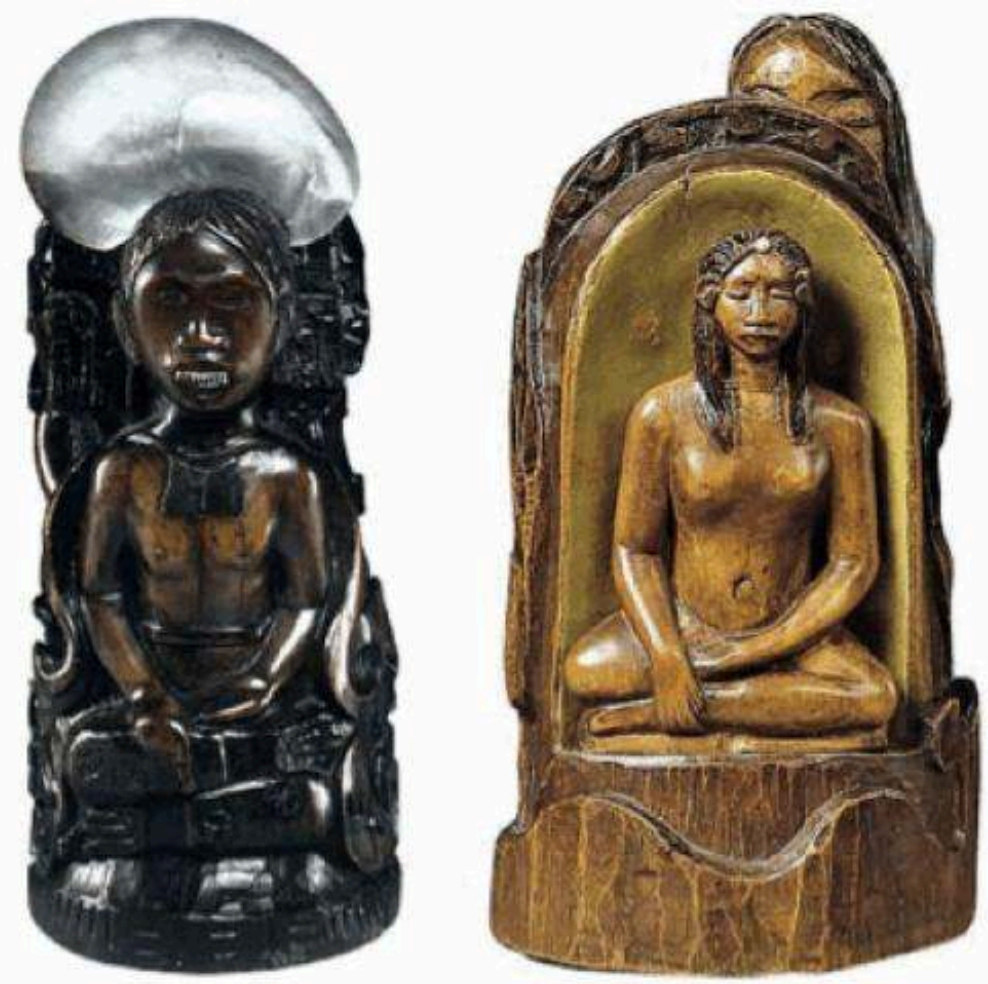

Paris, musée d'Orsay. Photo RMN - Gérard Blot et Idole à la perle, fin 1892-début (1893) Paris, musée d'Orsay. Photo RMN - H. Lewandowski.

\section{Reception en el siglo xx: el cosmopolitismo}

Salgamos entonces de esa década de los años 20 para incluir ahora en nuestro trabajo algunos representantes del aparato crítico de todo el siglo XX, ya que "La negra" se convirtió durante ese siglo en la tela total, polimórfica por excelencia, capaz de producir significados contradictorios. Un detalle (los senos) puede dar una critica social como la de Aracy d'Amaral ${ }^{17}$, donde Tarsila recuerda las negras explotadas de la estancia de San Bernardo que se colgaban una piedra al pezón para alargarse los pechos y dar a mamar al niño atado a la espalda. Pero, treinta años después, en la visión de Armelle Enders "A negra" es una pintura histórica donde el artista renuncia al fácil exotismo de los criollos para expresar crudamente una sensualidad tropical ${ }^{18}$. Visitar estas diversas manifestaciones de la imaginación critica seria muy largo para el objetivo 
de este artículo. Hemos preferido mostrar en dos cuadros los críticos que han investigado sobre estos dos campos de fuerza. Son mayoritarios los del eje cosmopolita.

El cuadro muestra las diferentes imágenes que permiten establecer una genealogía modernista de la obra "a negra", acompañado de los autores que la han citado

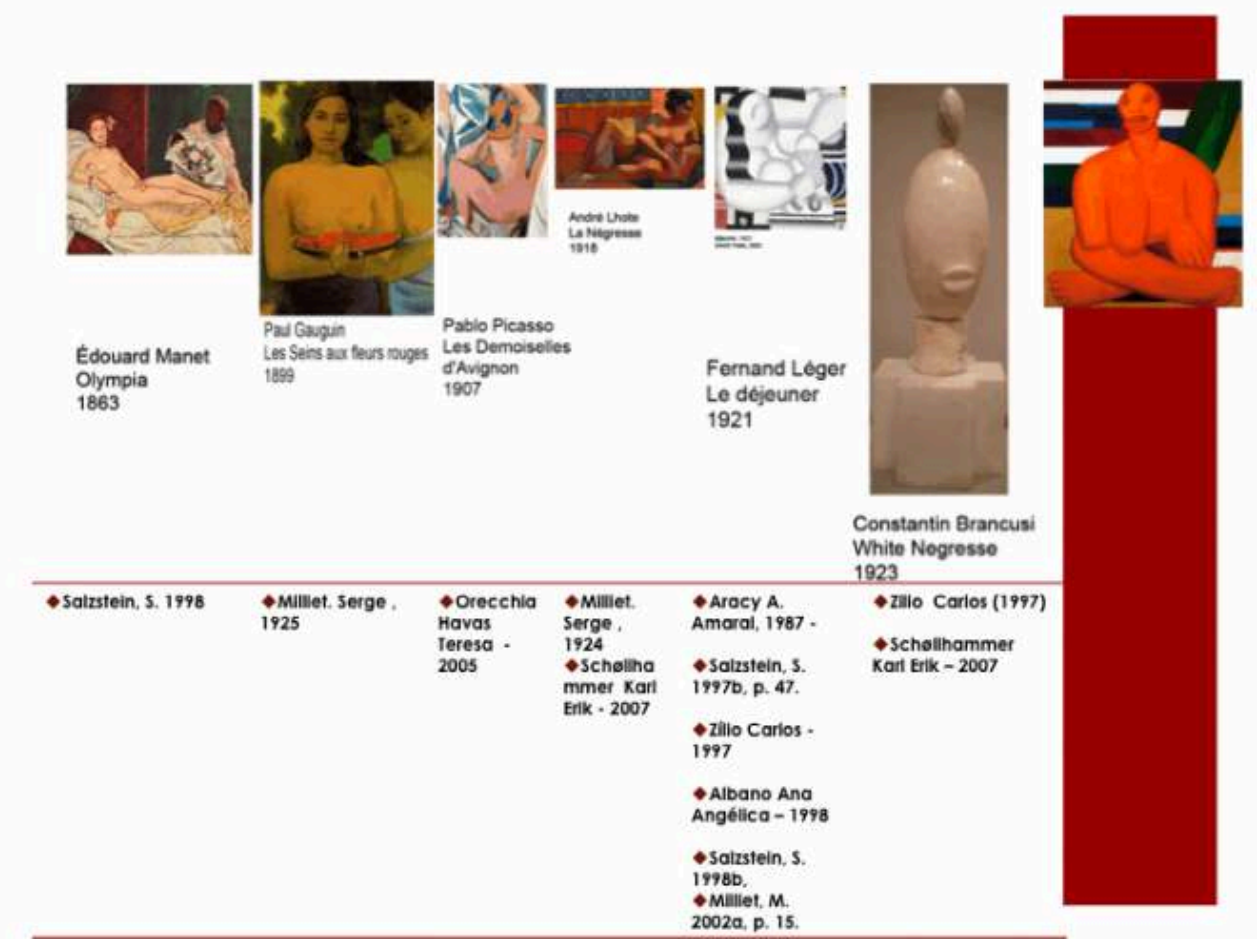

De Manet à Brancusi en el orden cronológico, se trata de mostrar en este gráfico las diferentes imágenes que han sido privilegiadas por los críticos. Es remarcable como la puesta en serie gráfica de los precursores de Tarsila enriquece la comprensión general del cuadro en cuestión. Este tipo de series interroga la utilización del termino "influencia". Este concepto nos viene del latín, pero es del francés del siglo XIII que nos llega la definición actual utilizada en crítica de arte, como "une action lente et continue exercée par une personne, une chose sur une autre personne ou chose". En efecto, si se puede estar de acuerdo con Salzstein (1998: 356) de que "A Negra" después de todo, "revela algo de la amenazadora vulgaridad de la Olympia de Manet, sólo que extravagantemente aplicada a la lujuria de la selva brasileña"19. También hemos visto que Gauguin anteriormente es una influencia importante remarcada en el período de creación de "A negra" desaparecida como la de Figari luego. El parecido de los elementos iconográficos en ambos pintores (Gauguin y Manet) son razonablemente justificados (el color de la piel, el desnudo, la postura). Encontraremos la misma problemática con las obras de Picasso del cual dice Teresa Orecchia Havas, (2005:155) que Tarsila, descubre el arte negro con Picasso y otros cubistas. Ya veremos un poco más tarde que las confluencias entre Tarsila y Picasso merecen un estudio mucho más importante. Intentaremos hacer una primera aproximación a éste tema en la conclusión.

Pero como escribió Sérgio Milliet, en 1924, en la Revista do Brasil, André Lhote fué su primer maestro. Las investigaciones formales de Lhote y Gleizes le permitieron "una reacción contra el bolchevismo impresionista". Lhote fue el puente entre el cubismo y 
el academicismo ${ }^{20}$. Cuando dejamos de lado la "amenazadora vulgaridad" del desnudo de Lhote, salta a la vista las homologías cromáticas entre los dos cuadros. Por otra parte la mayoría de los críticos lo remarcan, Léger es el profesor de Tarsila en esa época y "A negra" fue creada mientras estaba tomando lecciones con el francés en París. La relación Léger-Tarsila es la más glosada y se repite en los trabajos analíticos la anécdota sobre que, el cuadro dejo tan impresionado a su maestro que lo mostró a todos sus alumnos, diciendo que era un trabajo sobresaliente. Se anota profusamente las relaciones amistosas y las afinidades de personalidad entre los dos pintores ${ }^{21}$.

Finalmente, poco antes de que la pintora brasileña cree la pieza que estudiamos, visitará el Atelier Brancusi. Ella estuvo entonces muy impresionada por la estátua llamada 'La négresse' o "la négresse blanche", la cual inspirará la pintora brasileña ${ }^{22}$. Los labios gruesos y claramente sobresalientes son un dispositivo visual común de las dos obras. Remárquese que las dos obran aparecen el mismo año. Esta breve visita por las influencias cosmopolitas del objeto de estudio, nos permite de anotar las variables que están en juego en la inspiración de una obra. Ella son propias a la proximidad geográfica (todos son pintores que se desenvuelven profesionalmente en Paris) o amistosa y profesional (volveremos a esta variable social que es sin duda importante en la producción artística), iconológica o de homología formal e incluso cromática.

\section{Inspiraciones nacionales}

En el eje de críticos que privilegian las inspiraciones nacionales o regionales hay que comprender varios autores, pero trabajaremos solo sobre el proyecto de Maraliz de Castro Vieira Christo ${ }^{23}$. Este es muy interesante porque admitiendo que 'A negra' de Tarsila es un arquetipo del cual no quisiera negar su importancia histórica, se plantea un cuestionamiento sobre la militancia modernista de ciertos críticos que trabajan sobre esta pintura. Por ejemplo, la historiadora Aracy Amaral reconoce la tradición anterior, pero con el único objetivo de demostrar la novedad del artista de São Paulo. Christo dice que el tema del negro ha sido objeto, en Brasil, de artistas anteriores (como Andrade Brocos Modesto, Lucilio Albuquerque, entre otros, e incluso los dibujo de los años 20 que les he mostrado al principio de Do Rego Monteiro). Insiste en la importancia de otro pintor del mismo tema, Armando Vianna. Creo sin embargo, que en esta genealogía de la figura negra en la pintura del Brasil, se olvida Jean-Baptiste Debret sobre el cual un importante trabajo llamado "A Construção Francesa do Brasil" habia sido publicado un año antes ${ }^{24}$. Sin embargo, quisiera mostrarles una fotografía de un ex-empleado de la familia (tomado del articulo tan interesante de Christo) que muestra la foto de la nodriza de Tarsila. 


\section{L'axe régionaliste} - CHRISTO, Maraliz de
Castro Vieira. 2009

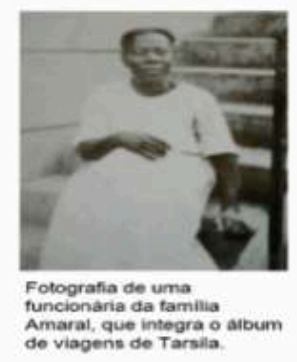

- Amaral, A. 1967

- Alvarado, Daisy Peccinini

- Dantas, Vinicius. 1997b,

- Salzstein, S. 1998b

Pero también, dice Christo, "cada vez que veo una reproducción de una imagen pequeña del siglo XIX de Iemanjá (ver arriba), no puedo menos que reconocer en ella a la negra de Tarsila". Esta referencia de Christo sobre Iemanja sin duda es muy impactante (puestos que los parecidos son tales) pero olvida citar que este tema había sido trabajado en el año 1993 por Fatima Bertch en un libro publicado en Nueva York por el MOMA, y retomado en español por Isabel Tejeda Martin en $1996^{25}$.

No terminaré este rápido análisis sin citar otro aspecto de la vertiente regionalista que prioriza la relación de Tarsila con la localidad de Sao Bernardo (y no con la ciudad de San Pablo) y con la región de Rafard. En este contexto está la creación del Memorial y museo Tarsila do Amaral gracias al Departamento de Cultura da prefectura Municipal de Rafard y la biografía de Tarsila do Amaral por Tarsila do Amaral la sobrina nieta del artista hija del sobrino de Tarsila y el último procurador legal de la "fazenda São Bernardo".

\section{Historia cultural/historia social}

Hemos visto como en la apreciación de un mismo cuadro había atribuciones fundamentalmente diferentes por ejemplo entre la negra explotada de Aracy Amaral y la sensualidad tropical de Armelle Enders. Tenemos así un grupo de críticos analizando la obra de Tarsila, que estaría privilegiando un eje cultural, una « historia cultural de lo social » una historia que pasa fundamentalmente por el tema de la búsqueda de una identidad nacional. En este grupo podríamos instalar el proyecto de Zilio de mostrar en Tarsila y otros pintores de su época una estrategia consciente y crítica de la construcción de la identidad cultural gracias a la apropiación de influencias 
extranjeras. Por ejemplo Zilio explica las influencias de Brancusi sobre Tarsila recordando primero el entusiasmo que existía en el ambiente parisino por el primitivismo. En este sentido, París provoca una reacción sobre nuestra pintora donde el arte negro funciona como una "sugerencia plástica" par la cual Tarsila recupera la nodriza de su infancia, inspirándose en los mitos de la estancia ${ }^{26}$.

En este grupo pero ya avanzando hacia el polo social (incluso por una cuestión disciplinaria, su libro se plantea el análisis de las redes de sociabilidad) podríamos ubicar los trabajos de Sergio Miceli. En su libro "Nacional estrangeiro", el autor analiza la red de relaciones entre artistas modernistas y mecenas de São Paulo como Paulo Prado. También investiga la relación entre la inmigración y el objeto artístico y las interacciones entre las vanguardias europeas y su impacto en la configuración de un lenguaje nacional, aspectos analizados en las obras de Tarsila Amaral y Antonio Gomide. En última instancia -explica - la influencia de Léger sobre Tarsila permite a esta de "introducir variaciones en la matriz de composición de Léger, con el fin de dar un trato preferencial a ciertos elementos clave de su repertorio de temas y símbolos "nacionales", más tarde repetida por los críticos como lemas de la modernidad". ${ }^{27}$

Estos proyectos son en realidad cercanos pero también bastante distante de otro vecino, el de Aracy Amaral, que podríamos llamar el de una "historia social de la pintura" de inspiración marxista. En efecto, en sus dos obras fundamentales "Tarsila, sua obra e seu tempo" (1975), et "Arte para quê?: a preocupação social na arte brasileira, 1930-1970", se trata para Amaral de determinar la constante preocupación social en el arte brasileño y el arte de América Latina, con mayor énfasis a partir de la década de 1920.

Concretamente en su análisis de la negra recuerda también las escenas de su infancia, haciendo hincapié en la anécdota de la piedra colgada del seno, recuerdos de una familia des ricos latifundistas, donde las mujeres negras, generalmente hijas de esclavas, fueron las nodrizas ${ }^{28}$. Vemos, en este ejemplo, una relación muy fuerte entre historia cultural y historia social.

\section{Conclusión: por una historia de las confluencias}

Entre esas dos vías nosotros propondríamos una tercera posibilidad, la de una historia de las confluencias porque como lo analiza muy bien Miceli, entran aquí en juego la movilidad de estos pintores pero también de estos críticos (tanto Zilio como Miceli han hechos sus doctorados en la Univ. de Paris 8 y en la Escuela de Altos Estudios EHESS) donde las tensiones entre nacionalismo y cosmopolitismo colaboran para crear una obra universal. Esta colaboración esta enmarcada en otros fenómenos de la historia mundial $^{29}$ y tiene como motor la movilidad, las migraciones, que permiten las innovaciones como un elemento más del tejido cerrado del devenir mundo.

Esta "historia de las confluencias" pasa entonces por una multiplicación y una modificación de la jerarquía de los flujos culturales comprendidos en el examen de un objeto y se apoya en el análisis de vectores de mundialización, macro-procesos que modifican de manera importante el dominio artístico. Estos son las migraciones (Paris como espacio abierto y cosmopolita), las guerras ("A negra" es creada entre dos guerras mundiales) pero también como lo podemos comprender en la recuperación de Tarsila por la "Fazenda Sao Bernardo", en el turismo. 
Acto seguido desearía poner un ejemplo de como podría operar este concepto de confluencia (a partir de la fragmentación de la obra literaria o artística y del análisis de su recepción) funcionando a partir de una trayectoria de los objetos y que se apoyaría en esta capacidad del arte del siglo XX (que ya hemos analizado bajo el termino de "Revolución Icónica") de dejar atrás la tradición. Se trata primero de una confluencia de encuentros. Porque esta facultad de innovación, en el caso de Tarsila, va de la mano de una sociabilidad importante y de la colaboración con una escuela de pintores inspirando su obra. Es decir que el efecto de grupo es importante. Todos los pintores enumerados par Anaïs Fléchet ${ }^{30}$ en las reuniones parisinas de Tarsila (Léger, Brancusi, Lhote, etc.) los hemos visto en la lista de precursores anotados por los críticos.

Pero el termino confluencia también funciona para Tarsila, en el sentido de un movimiento de asignación, de designación y de inspiración que va del presente al pasado. Es el pintor que elige sus precursores y dice - de manera consciente o inconsciente- a que precursor desea parecerse. Tarsila procede a una revolución icónica (como la hemos llamado) adoptando, en lugar del academismo reinante en Brasil, inspiraciones cubistas aprendidas en su estadía en Paris. Esta idea de confluencia puede apoyarse (más que en la dupla precursor-pintor) en el análisis de las series y en la acumulación de influencias diversas, un poco como en el sueño, de los objetos de la vida cotidiana y de la vida cultural, de la cultura popular y de la cultura erudita.

Un tercera acepción del termino de confluencia es la de un juego de interacciones múltiples de una obra con las obras que le son contemporáneas. Así, hemos visto como Picasso podría (con las Damas de Avignon) gracias a su período negro y a su rescate de las mascaras africanas incidir en el tema de la apropiación del arte negro que realiza la pintora brasileña. Pero el influjo puede ser también en el otro sentido y existe sin duda una resonancia entre las obras de Tarsila y de Picasso. Así, lo vemos en la exageración del tamaño de los senos, el detalle inundando el cuadro, técnica que Tarsila utiliza varias veces, y que encontramos solo un poco después (a partir del verano de 1927) en la serie de figuras de playa (imagen siguiente) de Pablo Picasso. 


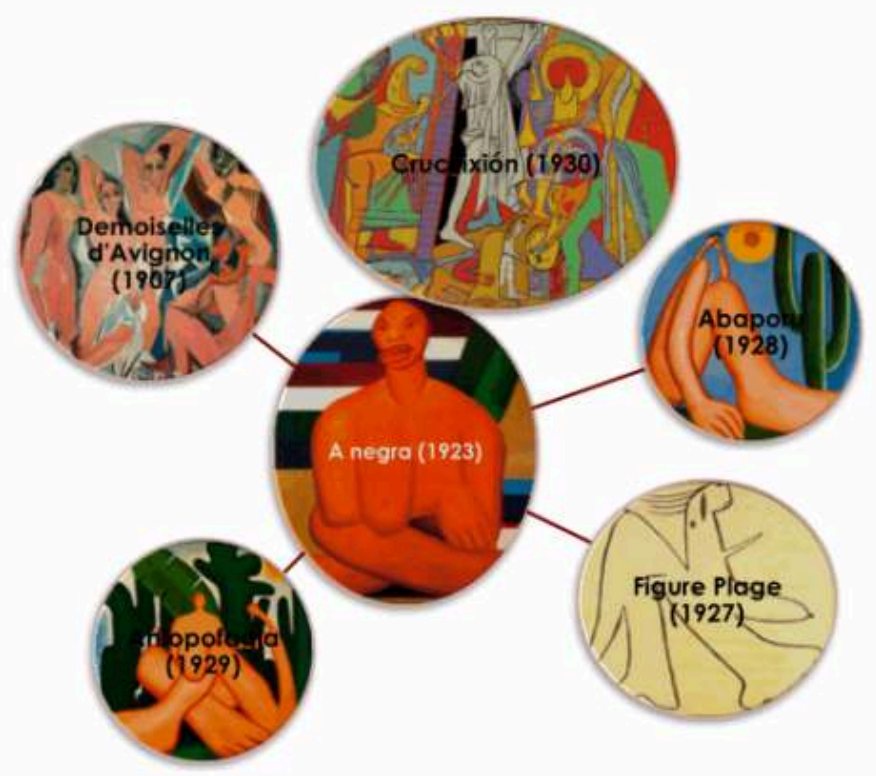

En estas se aprecia las similitudes entre las imágenes de Tarsila de 1923 y 1928 y las figuras de playa que Picasso comienza a pintar en 1927.

\section{BIBLIOGRAFÍA}

ALBANO, Ana Angélica. Tuneu, Tarsila e outros mestres-: o aprendizado da arte como um rito da iniciação. Grupo Editorial Summus, 1998.

ALMEIDA, María Cándida Ferreira de. Tornar-se outro: o topos canibal na literatura brasileira. Annablume, 2002.

AMARAL, Aracy A. Arte Para Quê ?: A Preocupação Social Na Arte Brasileira, 1930-1970. 3 éd. São Paulo: Studio Nobel, 2003.

AMARAL, Aracy A. Tarsila, sua obra e seu tempo. EdUSP, 1975.

AMARAL, Aracy A. “Artes visuais: do gesto criativo 'necessario'.” Minas Gerais: Suplemento literário. Imprensa Oficial do Estado de Minas Gerais, 1973

AMARAL, Aracy A. Textos do Trópico de Capricórnio: Modernismo, arte moderna e o compromisso com o lugar. Editora 34, 2006.

ANDRADE, Mário de, Tarsila, et Aracy A. Amaral. Correspondência Mário de Andrade \& Tarsila do Amaral. EdUSP, 1999. 
ANDRÉ, Marius. Peinture brésilienne. Revue de l'Amérique latine, Paris, 5 année, Tome XII, n. 56, p. 191-192, 1 mai 1926.

ARTELOGIE. “Brasil: cuestiones sobre el modernismo". Juillet 30, 2010, http://mascipo.in2p3.fr/ artelogie/spip.php?article2.

BIBLIOGRAPHIE DE LA FRANCE. Biblio: journal officiel de la librairie -Cercle de la librairie (Paris)-1972-1979

BUCH, Esteban. "La neuvième de Beethoven, une histoire politique". Bibliothèque des histoires. Paris. Éditions Gallimard. 1999

BULLETIN DE L'EFFORT MODERNE... -[s.n?] (Paris)-1924-

CENDRARS, Blaise. Feuilles de route: I. Le Formose. Dessins de Tarsila. Au sans pareil, 1924.

CHRISTO, Maraliz de Castro Vieira. "Algo além do moderno: a mulher negra na pintura brasileira no início do século XX. 1920”, Rio de Janeiro, v. IV, n.2, abr. 2009. http://www.dezenovevinte.net/ obras/obras_maraliz.htm

COGNIAT, Raymond. Au Salon des Indépendants. Revue de l'Amérique latine, Paris, 5 année, Tome XI, n. 53, p. 561-570, 1 mai 1926.

CHARTIER, Roger. “Le monde comme représentation.” Annales. Économies, Sociétés, Civilisations $44, n^{\circ} .6$ (1989): 1505-1520.

ENDERS, Armelle. Histoire du Brésil contemporain: XIXè-XXè siècles. Editions Complexe, 1997.

FLÉCHET, Anaïs. Villa-Lobos à Paris: Un écho musical du Brésil. Editions L’Harmattan, 2004.

FREITAS, Maria Teresa de Assunção, Claude Leroy, et Blaise Cendrars. Brésil: l'utopialand de Blaise Cendrars. Editions L'Harmattan, 1998.

FRÉROT, Christine. Le désir d'Amérique. De la nostalgie occidentale à l'affirmation du métissage américain: trois artistes d'Amérique latine en France, Artelogie. "Brasil: cuestiones sobre el modernismo". Febrero 2011

GRUSINSKI, Serge. Les Quatre Parties du monde: Histoire d'une mondialisation. Seuil, 2006.

HAVAS, Teresa Orecchia. Mémoire(s) de la ville dans les mondes hispaniques et luso-brésilien. Peter Lang, 2005.

LA FEMME DE FRANCE ['puis' et Mode et beauté]... -[s.n?] (Paris)-1915-1938

LA RENAISSANCE DE L'ART FRANÇAIS ET DES INDUSTRIES DE LUXE - La Renaissance (Paris. 1913) -[s.n.] (Paris)-1913-1931

LA RENAISSANCE: POLITIQUE, LITTÉRAIRE ET ARTISTIQUE / dir. Henry Lapauze. [s.n.] (Paris), 1913.

LE BULLETIN DE LA VIE ARTISTIQUE -Bernheim-jeune (Paris)-1919-1926

LEENHARDT, Jacques, Pierre Jozsa et Martine Burgos. Lire la lecture: essai de sociologie de la lecture. Arguments critiques, ISSN 0224-8808; 11. Paris: le Sycomore, 1982.

LEENHARDT, Jacques. A construção francesa do Brasil. São Paulo. Alderado \& Rothschild. Editora Hucitec. 2008.

MAUCLAIR, Camille. L'état actuel de la Peinture française. Revue de l'Amérique latine, Paris, 5 année, Tome XI, n. 53, p. 561-570, 1 mai 1926.

MERCURE DE FRANCE (Paris)-1890-1965 
MICELI, Sergio. Nacional estrangeiro. História social e cultural do modernismo artístico em São Paulo. São Paulo: Companhia das Letras. 2003.

MILLIET, Maria Alice. Emiliano Di Cavalcanti. Tarsila do Amaral e Di Cavalcanti: mito e realidade no modernismo brasileiro. Museu de Arte Moderna de São Paulo, 2002.

REVISTA DO BRASIL, Sâo Paulo, avril 1924, vol. XXV, no.100

SALZSTEIN, S. Dantas, Vinicius. 'Que negra é esta ?'. Catálogo Tarsila - Anos 20, SESI, Sao Paulo, 1997.

SCHAEFFER, Jean-Marie. Objets esthétiques? L'Homme, 170 | 2004, mis en ligne le 24 juin 2004. URL: http://lhomme.revues.org/index263.html. Consulté le 17 décembre 2010.

SCHMELING, Manfred, et Monika Schmitz-Emans. Multilinguale Literatur im 20. Jahrhundert. Königshausen \& Neumann, 2002.

SCHOLLHAMMER, Karl Erik. Além do visível: o olhar da literatura. 7Letras, 2007.

SCHOLLHAMMER, Karl Erik. Além do visível: o olhar da literatura. 7Letras, 2007.

SCHWARTZ, Jorge. Vanguardia y cosmopolitismo en la década del veinte: Oliverio Girondo y Oswald de Andrade. Beatriz Viterbo Editora, 1993.

SULLIVAN, Edward J. Arte latinoamericano del siglo XX. Editorial NEREA, 1996.

SULLIVAN, Edward J. Arte latinoamericano del siglo XX. Editorial NEREA, 1996.

“Tarsila do Amaral Catalogue Raisonné," sans date. http://www.base7.com.br/tarsila/.

TEJEDA MARTIN, Isabel. Do Amaral, Modotti, Izquierdo y Kahlo: cuatro artistas en América. Asparkía: investigació feminista, Núm: 7, 1996.

“The On-line Picasso Project”. Sam Houston State University and Texas University. April 1997. http://picasso.shsu.edu/.

VIDAL, Edgar. Littérature et société du Río de la Plata (1870-1940) - (Esquisse d'une théorie de l'objet littéraire), SCRIBD, 2006, disponible sur: http://halshs.archives-ouvertes.fr/ hal-00461161_v1/.

VIDAL, Edgar. Objets littéraires et bibliothèque d'objets dans la littérature du Río de la Plata (1870-1940), Nuevo Mundo Mundos Nuevos, Debates, 2010, [En línea], Puesto en línea el 23 marzo 2010. URL: http://nuevomundo.revues.org/59228. 2010

\section{NOTAS}

1. CHARTIER, Roger. "Le monde comme représentation." Annales. Économies, Sociétés, Civilisations 44, $\mathrm{n}^{\circ} .6$ (1989): 1505-1520.

2. LEENHARDT, Jacques, Pierre Jozsa et Martine Burgos. 'Lire la lecture: essai de sociologie de la lecture.' Arguments critiques, ISSN 0224-8808; 11. Paris: le Sycomore, 1982.

3. BUCH, Esteban. "La neuvième de Beethoven, une histoire politique". Bibliothèque des histoires. Paris. Éditions Gallimard. 1999

4. Nous avons défini cette figure du peintre ou de l'écrivain comme celle du "constructeur" VIDAL, Edgar. "Littérature et société du Río de la Plata (1870-1940) - (Esquisse d'une théorie de l'objet littéraire)", SCRIBD, 2010, disponible sur: http://halshs.archives-ouvertes.fr/.... 
5. GARDIN, Jean Claude. 'Le calcul et la raison: essais de formalisation du discours savant'. Éditions de l'École des Hautes Études en Sciences Sociales (Recherches d'histoire et de sciences sociales, 46). Paris. 1991

6. SCHAEFFER, Jean-Marie. Objets esthétiques ?. L'Homme, 170 | 2004, mis en ligne le 24 juin 2004. URL: http://lhomme.revues.org/index263.html. Consulté le 17 décembre 2010.

7. VIDAL, Edgar. 'Littérature et société du Río de la Plata (1870-1940) - (Esquisse d'une théorie de l'objet littéraire)', Ed.Publibook, Coll. Recherches, 2012, Paris. URL: http://www.publibook.com/ librairie/....

8. Encontramos muchos de estos tópicos en MILLIET, 2002

9. Por ejemplo DANTAS VINICIUS, 1995

10. Artelogie, 2010

11. Sobre este punto ver en este número mismo el comentario de: FRÉROT, Christine. "Le désir d'Amérique. De la nostalgie occidentale à l'affirmation du métissage américain: trois artistes d'Amérique latine en France", Artelogie. "Brasil: cuestiones sobre el modernismo". Printemps 2011

12. MAUCLAIR, Camille. L'état actuel de la Peinture française. Revue de l'Amérique latine, Paris, 5 année, Tome XI, n. 53, p. 561-570, 1 mai 1926.

13. Bulletin de L'Effort moderne 1926/12, p. 30

14. La Renaissance de l'art français et des industries de luxe, junio de 1926: 368

15. ANDRÉ, Marius. Peinture brésilienne. Revue de l'Amérique latine, Paris, 5 année, Tome XII, n. 56, p. 191-192, 1 mai 1926.

16. Ibid: 912

17. AMARAL, Aracy A. "Artes visuais: do gesto criativo "necessario"." Minas Gerais: Suplemento literário. Imprensa Oficial do Estado de Minas Gerais, 1973, p.33.

18. ENDERS, Armelle. Histoire du Brésil contemporain: XIXè-XXè siècles. Editions Complexe, 1997.

19. SALZSTEIN, S. Dantas, Vinicius. "Que negra é esta ?". Catálogo Tarsila - Anos 20, SESI, Sao Paulo, 1997, p.356.

20. REVISTA DO BRASIL, Sâo Paulo, avril 1924, vol. XXV, no.100, pp. 366.

21. ALBANO, Ana Angélica. "Tuneu, Tarsila e outros mestres-: o aprendizado da arte como um rito da iniciação”. Grupo Editorial Summus, 1998, p. 111

22. SCHOLLHAMMER, Karl Erik. "Além do visível: o olhar da literatura". 7Letras, 2007. p. 117

23. CHRISTO, Maraliz de Castro Vieira. "Algo além do moderno: a mulher negra na pintura brasileira no início do século XX. 1920", Rio de Janeiro, v. IV, n.2, abr. 2009. http:// www.dezenovevinte.net/obras/obras_maraliz.htm

24. LEENHARDT, Jacques. "A construção francesa do Brasil." São Paulo. Alderado \& Rothschild. Editora Hucitec. 2008.

25. TEJEDA MARTIN, Isabel. "Do Amaral, Modotti, Izquierdo y Kahlo: cuatro artistas en América”. Asparkía: investigació feminista, Núm.: 7, 1996, p.50.

26. ZILIO, Carlos. "A querela do Brasil: a questão da identidade da arte brasileira: a obra de Tarsila, Di Cavalcanti e Portinari, 1922-1945”. Relume Dumará, 1997, p. 49.

27. MICELI, Sergio. "Nacional estrangeiro. História social e cultural do modernismo artístico em São Paulo". São Paulo: Companhia das Letras. 2003, p. 138.

28. AMARAL, Aracy A. "Artes visuais: do gesto criativo "necessario"." Minas Gerais: Suplemento literário. Imprensa Oficial do Estado de Minas Gerais, 1973, p.33.

29. Nos ubicamos aquí en la línea de trabajos de Serge Gruzinski: "Les Quatre Parties du monde: Histoire d'une mondialisation". Seuil, 2006.

30. FLÉCHET, Anaïs. Villa-Lobos à Paris: Un écho musical du Brésil. Editions L'Harmattan, 2004, p. 83. 


\section{RESÚMENES}

El articulo se plantea el estudio de la recepción de dos obras de Tarsila do Amaral: "A negra" de 1923 y "Adoraçao" de 1925. Comenzando por un estudio de diarios y revistas de la década de 1920 en París, trabajaremos en particular los comentarios de la Revue de l'Amérique Latine (1926) llegando hasta las ultimas producciones de Aracy A. Amaral o mas recientemente Maraliz de Castro Vieira Christo. Estudiando como los críticos analizan "A negra", la recepción de esta obra muestra las tensiones entre las diversas concepciones nacionalistas y regionalistas y las que funcionan todavía hoy como el opuesto positivo o negativo, las influencias cosmopolitas. Finalmente, nos plantearemos algunos interrogantes sobre la manera en la cual opera la obra moderna, auto-instituyendo sus propias influencias.

\section{ÍNDICE}

Palabras claves: L'article examine la réception de Tarsila do Amaral (en particulier ses deux œuvres "A negra", 1923 et "Adoração", 1925). À partir d'une étude des journaux et des magazines des années 20 à Paris, et plus particulièrement des commentaires de la Revue de l'Amérique Latine (1926) en allant jusqu'aux dernières productions critiques d'Aracy Amaral, ou celles, plus récentes de Christo Maraliz et de Castro Vieira (2009). L'analyse de ces travaux montre les tensions et les grilles de perception: critères nationaux et régionaux ou influences cosmopolites. Mots-clés: do Amaral (Tarsila), Figari (Pedro), A negra, réception, oeuvre moderniste, Brésil, France 